Article

\title{
Cloud Computing Usage in SMEs. An Empirical Study Based on SMEs Employees Perceptions
}

\author{
Andra-Ileana Neicu ${ }^{1}$, Anamaria-Cătălina Radu ${ }^{2}$, Gheorghe Zaman ${ }^{2}$, Ivona Stoica ${ }^{2, *}$ (]) \\ and Florian Răpan ${ }^{3}$ \\ 1 Department of Marketing, Faculty of Marketing, The Bucharest University of Economic Studies, \\ 010404 Bucharest, Romania; andra.dobrescu29@yahoo.com \\ 2 Romanian Academy, Institute of National Economy, 050711 Bucharest, Romania; \\ anamaria_radu15@yahoo.com (A.-C.R.); gheorghezaman@ien.ro (G.Z.) \\ 3 Department of Public Relations, Faculty of Communication Sciences, "Dimitrie Cantemir" Christian \\ University, 40043 Bucharest, Romania; rapan_florian@yahoo.com \\ * Correspondence: stradivonas@gmail.com or ivonas@ase.ro; Tel.: +40-733503338
}

Received: 8 March 2020; Accepted: 16 June 2020; Published: 18 June 2020

check for updates

\begin{abstract}
This paper aims to determine the perception of small and medium-sized enterprises (SMEs) employees regarding the usage of cloud computing services in their activities. The quantitative study was conducted on a sample of 315 respondents employed in Romanian SMEs. Testing of the conceptual model was performed with the WarpPLS 3.0 software. The study aimed to test how several constructs-the perceived benefits, disadvantages and risks, communication process, overall experience of using cloud computing services, perceived image, and empathy regarding the cloud computing services-influence the perception of the cloud computing service quality among SMEs employees. Moreover, employees' perception regarding the satisfaction of using cloud computing services based on the perceived quality was also tested. We concluded that the perceived benefits and disadvantages of cloud computing service usage, the perception of both the communication process and users' experience regarding cloud computing service use, empathy, and cloud computing service image positively influence the perceived quality of the cloud computing service usage in SMEs. We did not find evidence that the perceived risks significantly influence the perceived quality of cloud computing services. Finally, we demonstrated that the perceived quality of the cloud computing services positively influences the satisfaction regarding cloud computing services among SMEs employees.
\end{abstract}

Keywords: cloud computing; SMEs; employee satisfaction; employee perceptions

\section{Introduction}

It is a well-established fact in the literature that small and medium-sized enterprises (SMEs) have generally more difficult access to finance. Coupled with the fact that SMEs, in contrast to the large-sized companies, are more vulnerable to external and internal financial shocks, it makes difficult for them to invest in, Information Technology and Communications (IT\&C), reducing their competitiveness. However, they have the advantage of better flexibility and fast adaptation to changes in the environment, market, and customer preferences [1].

Due to their flexibility and ability to adapt to disruptive technological changes, a large part of the high-growth SMEs, especially in emerging or high-tech industries such as IT, nanotechnologies, or bio-engineering, represents the vanguard of the early adopters of innovative technologies. SMEs may also fulfil complementary roles for large-sized companies along which they operate in extensive network systems. 
Incentives are needed to foster investments in both software and hardware capabilities for SMEs to capitalize on high-growth periods but also to better cope with less favorable periods. IT\&C technologies may comprehensively facilitate economic and social efficiency and improve SMEs competitive stance.

Cloud computing brings flexibility and cost-effectiveness benefits to SMEs, supporting the availability of data and services needed. It may overcome the weaknesses of conventional servers to provide faster, scalable, and efficient services, enabling profits through improved internal processes such as better organization, faster decision making, and accelerating communication with clients [2]. However, there are still SMEs hesitating to use cloud computing services (CCS) since additional risk-level challenges occur as these services are managed by third parties, making it more difficult to maintain privacy [3,4]. Therefore, cloud computing adoption can be facilitated by analyzing the pros and cons for the company [5]. Entrepreneurs support the decision to use cloud computing services CCS, acting either as initiators or endorsers to this technology [6]. SMEs need support to adopt cloud computing as a tool to survive and develop in the era of industry 4.0 [7].

The manuscript is structured as follows: the first section presents the literature review focused on CCS and cloud models; the second section presents the materials and methods used in terms of sampling, regression model, research design, the conceptual definition of the constructs, and hypotheses formulation; the third section presents the results and their discussion, along with the hypotheses test results; finally, the last section presents the conclusion, its contributions, and limitations.

\section{Literature Review}

The information society implementation has accelerated at a fast pace in the recent decade and the changes are very dynamic [8]. The power of digital society involves the economic and social evolution and progress, leading to the development of information society. Information and knowledge can be accessed by anyone from anywhere and at any time, increasing the chances for knowledge sharing and application [9]. The advantages of online communication are multiple: it provides an increased volume of information; it is interactive, hence easily accessible; and it can be used at any time [10].

The deep changes in the economy determined by the transition to the knowledge economy and knowledge management are reflected in new SMEs strategic approaches [11]. Following the mentioned facts, it is clear that knowledge and ability to use human resources effectively are key factors necessary for company growth [12]. With a fast-pace digital transformation of the business environment, people's digital skills are continuously improving. In this vein, SMEs are among the first to capitalize on this trend. Making use of cloud computing may prove critical for their competitiveness compared with large-sized companies.

Cloud computing is defined [13] as "a model for enabling convenient, on-demand network access to a shared pool of configurable computing resources that can be rapidly provisioned and released with minimal management effort or service provider interaction." It enables applications, storage spaces, network elements, and development platforms to be made available to users [14]. The term "cloud computing" can be adapted to the action of accessing information from everywhere and anytime by the basic use of a web platform with the help of a stable Internet connection.

Cloud computing may prove important for SMEs because it allows clients to access almost unlimited computing power without major investments in the infrastructure [15]. They provide on-demand self-service, broad network access, resource pooling, rapid elasticity, and measured service $[16,17]$. Top management support, firm size, and technological readiness are considered as key factors for cloud computing adoption [18].

(a) The public cloud. It is intended for the use by any company, regardless of its size. From the costs' point of view, the public cloud is considered less costly for clients. Its main characteristic is that the physical infrastructure is based at the CCS provider. In order to ensure high availability for the services, the provider must hold several processing centers, located in different geographical areas. In this way, the client can choose a data center, depending on the minimum distance between the data center and the company's headquarters. In terms of advantages, the public cloud has the lowest 
fares and multiples possibilities to purchase only specific services, such as storage space or computing power, according to the company's needs, on determined periods of time, further decreasing the costs. In terms of disadvantages, one issue is personal data protection, which makes, for instance, the process of cloud adoption by large European companies less common than in other parts of the world [15]. Another issue regards potential security breaches; the data could be accessed by the other users. In addition, if choosing a public cloud, the data will pass a public infrastructure on the Internet until they reach the storage server. As a result, these could be intercepted and decrypted [15].

(b) The private cloud. It is developed at an organizational level, where its resources are used only by the company. The private cloud is either administered on its own or outsourced; equipment and licenses are owned by the company, while maintenance usually comes as the company's responsibility [15]. Before implementing this type of cloud, the company must know which services are required (e-mail, storage, and processing power) in order to determine the type of infrastructure, considering that an intricate infrastructure will increase the initial investment costs, as well as the operational and maintenance costs. Compared to classic data centers, the private clouds provide augmented capacity to provide high quality dedicated services-to improve the processing power, which for a classic data center is horizontal, whilst the clouds have a vertical organization-meaning to add services. However, private clouds require compliance with specific standards, such as TIA-942. Most of the time standardization implies additional costs generated by electric energy supply requirements, acclimatization, fire prevention, or security [19].

(c) The hybrid cloud. It combines the already existing infrastructure (usually a private cloud) with the specific functions of the public cloud. In theory, any alternative of the two types could be implemented, but in practice, this is quite difficult since the specific applications or services are not always compatible and very much dependent on the speed of data transfer. That is why the public cloud can usually be used as an extension of the private one, with various non-essential processes of the company or resource-consuming processes kept in the public cloud. The hybrid cloud has, as the main advantage, the balance between the economical, technical, and security aspects [19]. Other advantages regard their costs and the opportunity of storing data at the same time, both in the private and public clouds. In terms of disadvantages, combining two different clouds is often difficult. It is quite possible that, even though both clouds are working separately, in the presumptive situation in which the provision of services is interrupted because of connection loss, the hybrid CCS won't be available at all. The use of a hybrid cloud takes some of the public cloud's disadvantages in terms of security, such as the possibility of interception and decrypting.

(d) The community cloud. It comprises CCS mostly used by the communities of users that have the same purpose, the same security policies, and the same requirements. The operating costs are divided between several clients, with the cloud's resources being represented by the unused resources of the community members' computers. The advantage is given by the capability to benefit from large processing power and storage, at the minimum initial investment costs. The major disadvantage is given by the availability of these resources, often without ensuring a minimum amount of resources available. There is no regulation or specific responsibilities of each user or support/data consulting from a CCS provider. There are no licenses nor a standard method of payment for the services provided [20].

Depending on their specific requirements, each user can choose one of the existing cloud solutions. The National Institute of Standardization and Technology (NIST) is listing out the main categories of cloud computing (models and services): SaaS (Software as a Service), PaaS (Platform as a Service), and IaaS (Infrastructure as a Service) [21].

(a) Cloud Software as a Service (SaaS) is one of the most common cloud form used by ordinary users. Access to services is made via a web browser or dedicated applications. Cloud Service Provider (CSP) applications running on cloud infrastructure are accessible from various client devices through a client interface such as a web browser. Most of the time, SMEs choose SaaS CCS for the e-mail servers, servers that allow real-time communication, and storage servers. These services can be purchased at a low cost with monthly or yearly payments via subscription. The applications and CCS are managed by 
the CCS provider that has to update them and make safety copies. Another advantage given by the use of SaaS is that all the company's users operate with the same version of the application. Moreover, SaaS is accessible via the Internet, meaning that it offers mobility to the employees, being accessible from any device that has an Internet connection (laptop, PC, tablet, smartphone). Use of the Software as a Service (SaaS) cloud computing category, presents a series of benefits for SMEs: a fast development of the services due to standardization; high adoption rate due to the familiarity of the web browsers; reduced implementation and modernization costs; these aspects being the provider's duty of services; and last but not least, the minimum requirements of support.

(b) Cloud Platform as a Service (PaaS) assumes the user develops on the cloud infrastructure or acquires applications created using programming languages and tools supported by the provider. PaaS is a complex model of CCS, consisting of applications and services which other applications or services can be built over. In this way, the app developer adapts strictly to the business requirements and the client's necessities to secure the communication channels and to implement other security elements. Each platform has its own programming language and specific instruments, but the advantage is that of allowing the development of some interfaces that use known standards and are easy to implement and use as HTML5, JavaScript, etc. [22]. In addition, most CCS providers have integrated into their services the possibility to use the relational databases and NoSQL [23].

(c) Cloud Infrastructure as a Service (IaaS) allows the clients to create their own infrastructure of computers, networking, and storage. The CSP provides the user with storage, networks, and other resources enabling the consumer to use and run arbitrary software, which can include operating systems and applications. IaaS permits the client to use the cloud's infrastructure to implement and utilize operating systems and numerous apps [23]. In an IaaS model, the virtual resources are shared to dedicated devices, and when receiving a request from a service, it is redirected towards the real infrastructure in a transparent mode for the user [22]. In this way, the client doesn't have access to the physical equipment offered by the CCS provider, nonetheless, he has the responsibility to manage and configure accurately the operation systems, storage space, and installed apps. The cloud category that offers IaaS is, in fact, an app that manages virtual machines and virtual infrastructure and is similar to a VPS (virtual private server) in the sense of paid hosting by the client for the personal virtual server.

By using cloud computing, SMEs can better capitalize on the emerging opportunities, allowing them to compete in an innovative business environment, by providing the tools needed to succeed [16]. Benefits such as up-to-date low-cost software solutions, virtually unlimited data storage, access to data from anywhere and anytime, high levels of security, or simplified data management may prove important for SMEs [24]. As with any technology, there are also several limitations, such as the reliability and security of data, the accessibility during power outages, or the lack of control [25].

\section{Materials and Methods}

\subsection{Research Sample}

The general research population was made of the Romanian SMEs that integrate CCS in their activity, while the survey unit was represented by the employees of those companies.

It was decided to use a simple transversal type of research, meaning that the research was done once at the level of a certain number of respondents [26]. The research method employed was the survey, and the instrument used to collect data was the online ad hoc survey [26].

Regarding the sample dimension the following formula was used:

$$
\mathrm{N}=\frac{t^{2} \times p \times(1-p)}{\Delta \omega^{2}}
$$

where $\mathrm{N}$ represents the required size of the sample; $t$ is the coefficient associated with the probability to guarantee the results; $p$ represents the share of respondents with the required characteristics, and $\Delta \omega=$ maximum admitted error (limit of error). 
Therefore, we decided to establish the sampling dimension, taking into account the following parameters: the coefficient associated to the probability to guarantee the results of $95 \%$ (respectively, $t=1.96)$, a maximum admitted error of $\pm 5 \%$ with a $p$ value of 0.5 . In this way, we concluded that the required sample had 385 subjects. However, due to financial restraints, we decided to further reduce the sample to 315 respondents. This was made possible because the respondents were employed by 95 SMEs, with an average of four respondents per company; our reduction of the sample meant three respondents per company, a change which, in our opinion, did not influence the results, even though we lost some statistical power. The sample structure is presented in Table 1.

Table 1. Sample structure.

\begin{tabular}{|c|c|c|c|c|c|c|c|}
\hline Character & tics & $\mathbf{N}$ & $\%$ & Ch & acteristics & $\mathbf{N}$ & $\%$ \\
\hline \multirow{4}{*}{$\begin{array}{l}\text { Company age } \\
\text { (years since } \\
\text { establishment) }\end{array}$} & $\begin{array}{c}\text { Less than } 5 \\
\text { years old }\end{array}$ & 24 & $25.26 \%$ & \multirow{2}{*}{$\begin{array}{l}\text { Respondent } \\
\text { gender }\end{array}$} & Male & 173 & $54.92 \%$ \\
\hline & $\begin{array}{c}5-10 \\
\text { years old }\end{array}$ & 36 & $37.89 \%$ & & Female & 142 & $45.08 \%$ \\
\hline & $\begin{array}{c}10-15 \\
\text { years old }\end{array}$ & 19 & $20.00 \%$ & \multirow{3}{*}{$\begin{array}{l}\text { Respondent } \\
\text { education }\end{array}$} & ISCED 4 or less * & 26 & $8.25 \%$ \\
\hline & $\begin{array}{l}\text { More than } \\
15 \text { years old }\end{array}$ & 16 & $16.84 \%$ & & ISCED 5 and 6 * & 206 & $65.40 \%$ \\
\hline \multirow{4}{*}{$\begin{array}{c}\text { Company size } \\
\text { (no. of employees) }\end{array}$} & Micro $(<10)$ & 26 & $27.37 \%$ & & ISCED 7 or more * & 83 & $26.35 \%$ \\
\hline & $\begin{array}{l}\text { Small } \\
(10-49)\end{array}$ & 53 & $55.79 \%$ & \multirow{3}{*}{$\begin{array}{l}\text { Respondent } \\
\text { age }\end{array}$} & $\begin{array}{c}\text { Young } \\
(<30 \text { years old })\end{array}$ & 94 & $29.84 \%$ \\
\hline & \multirow[t]{2}{*}{$\begin{array}{l}\text { Medium } \\
(50-249)\end{array}$} & \multirow[t]{2}{*}{16} & \multirow[t]{2}{*}{$16.84 \%$} & & $\begin{array}{c}\text { Middle-aged } \\
(31-50 \text { years old })\end{array}$ & 183 & $58.10 \%$ \\
\hline & & & & & Old ( $>50$ years old) & 38 & $12.06 \%$ \\
\hline
\end{tabular}

* ISCED = International Standard Classification of Education. ISCED 4 or less is roughly equivalent up to post-secondary non-tertiary education. ISCED 5 and 6 is equivalent to short-cycle tertiary education and a bachelor's degree or equivalent. ISCED 7 or more represents a master's or doctorate degree.

\subsection{Regression Model}

From a conceptual point of view, the research contributes to the fact that a regression model is used to analyze the intensity of the relationship between factors. Regarding the connection types existing at the analyzed dependent and independent construct level, the conceptual model can be described as a multiple regression model:

$$
\begin{gathered}
\text { Quality }(\mathrm{Y})=\beta 0+\beta 1 * \text { Benefits }\left(\mathrm{x}_{1}\right)+\beta 2 * \text { Disadvantages }\left(\mathrm{x}_{2}\right)+\beta 3 * \operatorname{Communication}\left(\mathrm{x}_{3}\right) \\
+\beta 4 * \text { Experience }\left(\mathrm{x}_{4}\right)+\beta 5 * \operatorname{Risks}\left(\mathrm{x}_{5}\right)+\beta 6 * \operatorname{Empathy}\left(\mathrm{x}_{6}\right)+\beta 7^{*} \operatorname{Image}\left(\mathrm{x}_{7}\right)+\varepsilon
\end{gathered}
$$

\subsection{Survey Design}

Data collection was made by a questionnaire comprising 34 questions, including closed, open, and mixed questions. The majority of questions were measured on a 7-point Likert scale, except those addressing the demographic characteristics of respondents and the parameters of the companies investigated. The questionnaire was divided into 10 parts: the first one comprised questions regarding the age, education, and position in the company of the respondents, the size of the company, and number of years since establishment; the second part regarded the perceived benefits of CCS, comprising questions describing the ability of CCS to facilitate the data storage process, the possibility of providing instant data access, without any delays, their ability to provide large storage space, facilitating access to stored data, etc.; the third part described the perceived disadvantages of CCS, such as access to a secure and high-speed Internet connection in order to have access to the data stored in the cloud, the lack of information on the geographical location of the servers where the data were stored, the users' 
concerns in terms of the security and integrity of the stored data, as well as the applications integrated in the cloud, which they used in their daily activity; the fourth part focused on the perception of the communication process in CCS, with questions regarding the availability of informative materials about CCS from the representatives of their provider, from the direct or indirect cloud service providers, discovering information specific to CCS through online advertising, and taking the individual initiative to search for information on the subject; the fifth part described the perception of users' experience regarding CCS regarding the way in which information about CCS was acquired after participating at a conference from the domain or at a conversation with experts in that domain and how these helped the respondents to efficiently integrate these services in their activity; the sixth part is focused on the perceived risks regarding CCS use, such as the risks associated to the CCS usage and the constraints due to the potential dangers involved by the loss of data, lack of security regarding personal data, or by the impossibility of having permanent access to the data stored in the cloud; the seventh part described the empathy toward CCS and comprised questions regarding the respondents' receptivity toward their use, the way the company encouraged the respondents to integrate CCS in their daily activities, and how service providers understand customer needs and integrate them in their CCS; the eighth part comprised questions regarding the CCS image for respondents, namely the extent CCS adapt to the requirements of the users, respectively their ability to be integrated on a platform; the ninth part of the questionnaire highlighted the perceived quality of the CCS; finally, the last part focused on the perceived satisfaction regarding CCS, where the respondents were asked to rate their satisfaction regarding the use of CCS within their company.

In the first pre-testing performed on 12 individuals, several errors regarding the phrasing and potential misunderstandings were identified. The second pre-testing was performed on a smaller number of individuals, with a sample of six CEOs.

The first round was conducted from 1 March to 1 June 2017. We continued the research in 2019 and gathered additional data. The second round of questionnaires was distributed in the period of February-April 2019. For data collection, we used the Lime Survey platform. The potential respondents received the customized participation invitation to their e-mail address and the necessary information to access the survey on the Lime Survey platform.

To test the conceptual model, the WarpPLS 3.0 software package was used. The regression analysis had the purpose to illustrate the way in which a series of factors had the capacity to influence the respondents' perception regarding the quality of the CCS used.

\subsection{Conceptual Definition of the Constructs and Hypotheses Formulation}

To define the research hypotheses, the following models were reviewed: the SERVQUAL model [27], SaaS-QUAL model [28], TAM model (Technology Acceptance Model) [29-31], and TOE model (Technology-Organization-Environment) [32].

The conceptual model comprised the following constructs:

(a) Perceived benefits of cloud computing services (Benefits). A latent construct, it describes the main advantages of CCS use as a result of their integration in employees' activity. The construct consists of seven items covering issues such as the ability of CCS to facilitate the data storage process, the possibility of providing instant data access, without any delays, and their ability to provide large storage space, facilitating access to stored data, eliminating restrictions on the type of device connected to the Internet, from which access to the cloud is made. Furthermore, the barrier to cloud access from a particular location is removed and information stored in the cloud is allowed access to other employees.

(b) Perceived disadvantages of cloud computing services (Disadvantages). A formative construct, it comprises five items describing access to a secure and high-speed Internet connection in order to have access to the data stored in the cloud, the lack of information on the geographical location of the servers where the data are stored, the users' concerns in terms of the security and integrity of the stored data, as well as the applications integrated into the cloud, which they use in their daily activity. 
In addition, another drawback is the support or other training that respondents must receive from cloud service providers.

(c) Perception of the communication process in cloud computing services (Communication). The communication process within CCS represents a critical pillar for extensive use of these services. As the information regarding CCS is better understood, the users can improve their performance by the efficient use of the cloud resources in their daily activities. The communication process can be looked at from three perspectives: from the staff's point of view and from the direct and indirect providers' of these types of services point of view. A formative construct, it describes items such as the availability of informative materials regarding CCS from the representatives of their company and from the direct and indirect cloud service providers. Moreover, discovering information specific to CCS through online advertising and taking the individual initiative to search for information about CCS can make a considerable contribution in terms of the knowledge of their use.

(d) Perception of users' experience regarding cloud computing services (Experience). A formative construct, it describes the personal experience of the employees regarding CCS use. It comprises two items regarding the way in which information about CCS acquired after participating at a conference from the domain or in conversation with experts in that domain helped the respondents to efficiently integrate these services into their activity.

(e) Perceived risks regarding cloud computing services use (Risks). A formative construct, it comprises four items related to the risks associated with CCS use and the constraints due to the potential dangers caused by the loss of data or lack of security regarding personal data or by the impossibility of having permanent access to the data stored in the cloud.

(f) Empathy toward cloud computing services (Empathy). A formative construct, it comprises three items describing the individual empathy—-the respondents' receptivity toward CCS; internal empathy, in which the company encourages the respondents to integrate CCS in their daily activities; and external empathy, where CCS providers understand customer needs and integrate them.

(g) Cloud computing services image (Image). A formative construct, it includes two items describing the extent CCS adapt to the requirements of the users, respectively to their availabilityto be integrated within a platform, when the operating system (OS) is not a decisive factor.

(h) Perceived quality of cloud computing services (Quality). It describes the respondents' perception regarding CCS quality.

(i) Perceived satisfaction regarding cloud computing services (Satisfaction). It describes the perceived satisfaction of the respondents regarding the usage of CCS within their company.

The scale validation is presented in Table 2 . All the construct items were measured on a seven-point Likert scale.

All items considered had factor loadings of 0.65 or higher, the acceptable threshold for samples of our size, thereby indicating satisfactory levels of convergence and discriminant validity.

The following research hypotheses were formulated:

H1. Perceived benefits of CCS use positively influences the perceived quality of the CCS in SMEs.

H2. Acknowledgement of the perceived disadvantages of CCS use positively influences the perceived quality of CCS in SMEs.

H3. Perception of the communication process in CCS positively influences the perceived quality of CCS in SMEs.

H4. Perception of users' experience regarding CCS use positively influences the perceived quality of CCS in SMEs.

H5. Perceived risks regarding CCS use positively influences the perceived quality of the CCS in SMEs.

H6. Empathy toward CCS use positively influences the perceived quality of CCS in SMEs.

H7. CCS image positively influences the perceived quality of CCS in SMEs.

H8. Perceived quality of CCS positively influences the perceived satisfaction regarding CCS in SMEs. 
Table 2. Scale validation. CCS: cloud computing services.

\begin{tabular}{|c|c|c|}
\hline Constructs & Loadings & Cronbach's $\alpha$ \\
\hline \multicolumn{3}{|l|}{ Benefits } \\
\hline ability of CCS to facilitate the data storage process & 0.809 & \multirow{7}{*}{0.842} \\
\hline possibility of providing instant data access & 0.722 & \\
\hline ability to provide large storage space & 0.793 & \\
\hline access to stored data & 0.889 & \\
\hline removing restrictions on the type of device connected to the Internet & 0.815 & \\
\hline access from a particular location & 0.837 & \\
\hline information stored in the cloud is allowed access to other employees & 0.83 & \\
\hline \multicolumn{3}{|l|}{ Disadvantages } \\
\hline $\begin{array}{l}\text { issues related to access to a secure and high-speed Internet connection in order to } \\
\text { have access to the data stored in the cloud, }\end{array}$ & 0.769 & \multirow{5}{*}{0.749} \\
\hline $\begin{array}{c}\text { lack of information on the geographical location of the servers where the data is } \\
\text { stored }\end{array}$ & 0.809 & \\
\hline users' concerns regarding the security and integrity of the stored data & 0.756 & \\
\hline users' concerns regarding the applications integrated in the cloud & 0.869 & \\
\hline lack of support or other training from cloud service providers. & 0.709 & \\
\hline \multicolumn{3}{|l|}{ Communication } \\
\hline $\begin{array}{l}\text { availability of informative materials regarding CCS from the representatives of } \\
\text { their company }\end{array}$ & 0.942 & \multirow{5}{*}{0.893} \\
\hline $\begin{array}{c}\text { availability of informative materials regarding CCS from the representatives of } \\
\text { direct CCS providers }\end{array}$ & 0.869 & \\
\hline $\begin{array}{c}\text { availability of informative materials regarding CCS from the representatives of } \\
\text { indirect CCS providers }\end{array}$ & 0.809 & \\
\hline available information regarding CCS through online advertising & 0.856 & \\
\hline taking the individual initiative to search for information about CCS & 0.784 & \\
\hline \multicolumn{3}{|l|}{ Experience } \\
\hline $\begin{array}{l}\text { how much the information about CCS acquired after participating at a conference } \\
\text { from the domain helped the respondent to efficiently integrate CCS in his activity }\end{array}$ & 0.746 & \multirow[t]{2}{*}{0.762} \\
\hline $\begin{array}{l}\text { how much the information about CCS is acquired in conversation with experts in } \\
\text { that domain helped the respondent to efficiently integrate CCS in his activity }\end{array}$ & 0.783 & \\
\hline \multicolumn{3}{|l|}{ Risks } \\
\hline risks associated with CCS due to the potential dangers involved by the loss of data & 0.863 & \multirow{4}{*}{0.816} \\
\hline $\begin{array}{l}\text { constraints associated with CCS due to the potential dangers involved by the loss } \\
\text { of data }\end{array}$ & 0.851 & \\
\hline $\begin{array}{l}\text { risks and constraints associated with CCS due to the potential dangers involved by } \\
\text { the lack of security regarding personal data }\end{array}$ & 0.811 & \\
\hline impossibility of having permanent access to the data stored in the cloud & 0.816 & \\
\hline \multicolumn{3}{|l|}{ Empathy } \\
\hline individual empathy-the respondents' receptivity toward CCS & 0.869 & \multirow{3}{*}{0.895} \\
\hline $\begin{array}{c}\text { internal empathy-the company encourages the employees to integrate CCS in their } \\
\text { daily activities }\end{array}$ & 0.783 & \\
\hline external empathy-CCS providers understand customer needs and integrate them & 0.856 & \\
\hline \multicolumn{3}{|l|}{ Image } \\
\hline the extent CCS provider adapt them to the requirements of the users & 0.823 & \multirow{2}{*}{0.817} \\
\hline $\begin{array}{c}\text { CCS ability to be integrated on a platform, when the operating system is not a } \\
\text { decisive factor }\end{array}$ & 0.811 & \\
\hline \multicolumn{3}{|l|}{ Quality } \\
\hline rate the perceived perception regarding CCS quality & 0.792 & 0.792 \\
\hline \multicolumn{3}{|l|}{ Satisfaction } \\
\hline rate the perceived satisfaction regarding usage of CCS within the company & 0.765 & 0.765 \\
\hline
\end{tabular}




\section{Results}

In order to observe if the constructs presented in the conceptual model level influenced the perception of the respondents regarding the quality of CCS, we assessed the beta coefficients and the significance. These two coefficients were used to either validate or not the research hypothesis. Results of hypotheses testing are presented in Table 3.

Table 3. Testing the hypotheses.

\begin{tabular}{ccccc}
\hline & Hypothesis & $\boldsymbol{\beta}$ & $\boldsymbol{p}$ & Condition \\
\hline H1 & Benefits-Quality & 0.33 & $<0.001$ & Validated \\
\hline H2 & Disadvantages-Quality & -0.10 & 0.04 & Validated \\
\hline H3 & Communication-Quality & 0.14 & $<0.001$ & Validated \\
\hline H4 & Experience-Quality & 0.11 & 0.03 & Validated \\
\hline H5 & Risk-Quality & -0.08 & 0.06 & Not validated \\
\hline H6 & Empathy-Quality & 0.48 & $<0.001$ & Validated \\
\hline H7 & Image-Quality & 0.21 & $<0.001$ & Validated \\
\hline H8 & Quality-Satisfaction & 0.83 & $<0.001$ & Validated \\
\hline
\end{tabular}

After the analysis we concluded that for seven out of the eight constructs tested, the conditions were met and only in the case of one were rejected. In order to validate a hypothesis, it has to meet two conditions at the same time, which are: $p$-value to be lower than 0.05 , while the $\beta$ coefficient must be higher than 0.1 .

Only one hypothesis didn't meet the conditions, which led to its rejection. It theorized that Risks regarding CCS use positively influences the perceived Quality of CCS. After the analysis was made, the results were $\beta=-0.08$, while $p$-value $=0.06$, larger than the 0.05 threshold.

In order to further test the validity of the model, another indicator was considered, namely the coefficient of determination $\mathrm{R}^{2}$. It describes the way independent constructs have the capacity to explain the variation of the dependent constructs. The determination coefficients are listed in Table 4.

Table 4. The determination coefficients.

\begin{tabular}{ccc}
\hline Quality & Image & Satisfaction \\
\hline 0.43 & 0.23 & 0.83 \\
\hline
\end{tabular}

The independent constructs have the meaning to explain more specifically the variation of the dependent constructs. In this way, the highest value for this indicator was registered at the level of Satisfaction. This aspect illustrates that these respondents' satisfaction regarding CCS is explained in a proportion of $83 \%$ by independent constructs, while in the case of Quality, it is explained in a proportion of $43 \%$ of independent constructs. The lowest value was registered at the level of Image. In this way, it is explained in a proportion of $23 \%$ at the variation of Empathy.

Aside from the previously mentioned indicators, additional indicators were calculated to further test the model. After testing the model, the results shown in Table 5 were achieved.

Average path coefficient (APC), average R-squared (ARS), and average adjusted R-squared (AARS) values were all below the threshold (5), while the $p$-value for all three indicators was under the threshold of 0.001 , which means that the model can be accepted.

In the case of the average VIF (AVIF), the acceptance condition was that its value must be lower than 5, ideally lower than 3.3. The achieved value was 1.415, therefore in this case the model can be accepted, too. In the case of the average full co-linearity VIF (AFVIF), with a value of 2.105, lower than the threshold, the condition is met, too. 
Table 5. Conformity measurement coefficients.

\begin{tabular}{cc}
\hline Indicators & Validation Criteria \\
\hline Average path coefficient (APC) $=0.286$ & $p<0.001$ \\
Average R-squared (ARS) $=0.451$ & $p<0.001$ \\
Average adjusted R-squared (AARS) $=0.447$ & $p<0.001$ \\
Average VIF (AVIF) $=1.415$ & Threshold $<5$, Ideally $<3.3$ \\
Average full co-linearity VIF (AFVIF) $=2.105$ & Threshold $<5$, Ideally $<3.3$ \\
Tenenhaus GoF (GoF) $=0.562$ & Small $>0.1$, Medium $>0.25$, Large $>0.36$ \\
Sympson's paradox ratio (SPR) $=1.000$ & Threshold $>0.7$, Ideally $=1$ \\
R-squared contribution ratio (RSCR) $=1.000$ & Threshold $>0.9$, Ideally $=1$ \\
Statistical suppression ratio (SSR) $=1.000$ & Threshold $>0.7$ \\
Nonlinear bivariate causality direction ratio (NLBCDR) $=1.000$ & Threshold $>0.7$ \\
\hline
\end{tabular}

The value of Tenenhaus GoF (GoF) was 0.562, larger than the maximum 0.36 threshold. Therefore, in this case, the model cannot be accepted. Sympson's paradox ratio (SPR) and R-squared contribution ratio (RSCR) both had a value equal to 1 , an ideal one in the testing of a conceptual model. The same value was registered for the statistical suppression ratio (SSR) and nonlinear bivariate causality direction ratio (NLBCDR).

\section{Discussion}

The originality of our study is generated by the fact that, until now, in Romania, no other study has been carried out regarding the use of CCS with a fairly similar degree of complexity. Moreover, the originality is also supported by the fact that this study identified several factors influencing the employees' perception regarding the CCS usage in SMEs.

The suggested conceptual model was designed to analyze the perception of the respondents on the quality of CCS that were available at the SMEs they worked at.

Several research hypotheses were developed, relying on several constructs in the conceptual model. The first two research hypotheses, regarding the correlation between the perceived benefits and disadvantages of using the CCS and the perceived quality of CCS in SMEs, proved to be true. SMEs employees considered the advantages offered by CCS from the perspective of data structure, of real-time access to information or to a high level of data, while in terms of disadvantages, it seems that they were able to understand and cope with issues such as access to a secure and high-speed Internet connection in order to have access to the data stored in the cloud, the lack of information on the geographical location of the servers where the data were stored, the users' concerns in terms of the security and integrity of the stored data, as well as the applications integrated into the cloud, which they used in their daily activity. It is worth mentioning that the perception of disadvantages had a negative correlation with the quality of CCS.

In addition, we analyzed the way in which the communication process had the capacity to influence the perception regarding CCS quality. We emphasized issues such as the information transmitted by SMEs staff, the services providers, or by the way in which the information was collected (online or offline). A direct and positive connection was found, even though the relationship was not very strong, meaning this construct had a small influence on the respondents' overall perception of quality.

The users' experience relationship with the perceived quality of CCS was further hypothesized. It was validated through the tests performed, illustrating a direct and positive connection between the two constructs. However, the connection was not very strong. Therefore, the personal experience of the employees regarding CCS usage, even though it helped SMEs employees to efficiently integrate these services into their activity, was not critical to the perception of the quality of CCS.

The hypothesis reffering to the risks associated with CCS use, such as data security, data storage, personal data storage, or the way of restraining data when the server is not functional was not accepted. The aforementioned risks did not have the capacity to influence employees' perception regarding CCS 
quality. In many situations at the company level, the employees are not aware of the risks they are exposed to, the IT department being directly responsible for this activity. This is one reason, in our opinion, explaining the hypothesis rejection.

Two other constructs, empathy and image, were proven as having a direct and positive relationship with the use of CCS in SMEs. This did not come as a surprise since, to some extent, these constructs involved all of the previous constructs. Empathy had the largest impact $(\beta=0.48)$, while for image $\beta=0.21$.

In addition, in this conceptual model, we wanted to identify the connection between the respondents' perception regarding CCS quality and the satisfaction they felt after using these services. We noticed that there was a direct and positive relationship between the two constructs. The value of the $\beta$ indicator was 0.83 . Regarding the $\mathrm{R}^{2}$ indicator, resulted positive and high values $(0.70)$, which suggests that satisfaction accounted for $70 \%$ in the overall variation of the model.

Cloud computing offers new solutions to SMEs problems and changes the way in which they do business. The purpose of cloud computing is to offer better and high-quality service at a lower cost, with not necessarily advanced IT staff. The perception of cloud computing is generally positive in Romanian SMEs, indicating a prospective increase in the number of SMEs adopting it in the future. Cloud computing most promising advantages, such as cost reduction, virtualization, and space preservation in terms of office space, can prove to be a solution to the financial constraints and resource difficulties of SMEs. We hope that these findings will help the entrepreneurs realize the challenges for increasing the positive perception of cloud computing. It offers an innovative business model for the pervasive, convenient, and on-demand access to the virtualized and distributed resources such as network, servers, storage, applications, and services [33]. Cloud computing increases the capacity of SMEs since it delivers services on a pay-per-use basis, which allows firms to regulate the usage level of information technology (IT) resources as per current demands. In the age of the Industry 4.0, which has brought digitization and automation to production and operation, the adoption and use of cloud computing have the potential to transform current SMEs delivering more agility, flexibility, and productivity [34]. It helps SMEs to transform the conventional business model, boost effective collaboration, and enhance IT capabilities [35].

The unique features, such as the on-demand service of cloud computing, have made it worthier for SMEs. With a relatively small IT budget, which does not allow them to develop IT resources internally, with inadequate technological competence and limited IT expertise, making them dependent on external IT professionals, cloud computing can create opportunities for SMEs to use modern technologies on a rental basis, which previously were unaffordable [36]. It may improve the decision-making process for SMEs, while they can effectively compete with large businesses leveraging these services [37]. However, cloud computing is not extensively adopted by SMEs [38]. Lack of awareness of the relative advantages is a major reason [39], along with other factors such as concerns about the security and privacy of resources stored in a third party's server [40] or entrepreneurs' personal attributes [41,42]. Additionally, one critical factor, addressed in our study, is the support received from cloud providers [39].

\section{Conclusions}

With an increased market competition and continuously changing business environment, SMEs are increasingly willing to adopt various information technologies such as the Internet of things (IoT), virtualization technologies, and cloud computing [33,34]. Cloud computing has received more attention due to the growing reputation of the shared networks connecting people from all over the world.

From the theoretical perspective, this study identified and empirically tested a set of items giving shape to CCS perception among SMEs employees. This contributes to the development of the literature focused on cloud service use. Further, this study extends the literature dedicated to cloud computing by exploring some new and relevant cloud computing-related constructs such as cloud provider's influence and perceived risks, items not widely assessed in prior research. 
From a practical perspective, the results are important for entrepreneurs because it provides them with the opportunity to identify the factors important for employees when they use CCS. With SMEs as an emerging market for cloud providers, this study will assist them in recognizing the influential factors of cloud adoption. SMEs are not well aware of the potential of adopting or using cloud computing, therefore, cloud providers should undertake various measures to increase the awareness of the benefits, focus on easy-to-use interfaces when designing CCS for SMEs, and offer clear instructions to guide users in SMEs on how to operate their services.

Taking all of these into account, we consider that the results achieved in this empirical study provide a significant contribution to understanding the incentives and rationale of implementing CCS in SMEs.

In terms of research limitations, there was no differentiation in sample selection between early and well established SMEs. CCS use may be different according to the business lifecycle, and this has to be further investigated. Secondly, the industry selected for the study is more prone to CCS usage than others. A broader selection of industries may provide different results, depending on the SMEs employees' use of CCS in their daily activities. Finally, this study investigated CCS usage in SMEs from the employees' perspective; future research may focus on entrepreneurs' and cloud providers' perspectives to have a comprehensive understanding of the CCS adoption process.

Author Contributions: Conceptualization, A.-I.N., A.-C.R., G.Z., I.S., and F.R.; methodology, A.-I.N., A.-C.R., G.Z., I.S., and F.R.; data curation, A.-I.N., A.-C.R., G.Z., I.S., and F.R.; writing-original draft preparation, A.-I.N., A.-C.R., G.Z., I.S., and F.R.; visualization, A.-I.N., A.-C.R., G.Z., I.S., and F.R. All authors have read and agreed to the published version of the manuscript.

Funding: This research received no external funding.

Conflicts of Interest: The authors declare no conflict of interest.

\section{References}

1. Ceptureanu, E.G.; Ceptureanu, S.I. The impact of adoptive management innovations on medium-sized enterprises from a dynamic capability perspective. Technol. Anal. Strateg. Manag. 2019, 31, 1137-1151. [CrossRef]

2. Armbrust, M.; Fox, A.; Griffith, R.; Joseph, A.D.; Katz, R.H.; Konwinski, A.; Lee, G.; Patterson, D.A.; Rabkin, A.; Stoica, I.; et al. Above the Clouds: A Berkeley View of Cloud Computing. Commun. ACM 2010, 53, 50-58. [CrossRef]

3. Hashizume, K.; Rosado, D.G.; Fernández-Medina, E.; Fernandez, E.B. An analysis of security issues for cloud computing. J. Internet Serv. Appl. 2013, 4, 5. [CrossRef]

4. Khalil, I.M.; Khreishah, A.; Azeem, M. Cloud Computing Security: A Survey. Computers 2014, 3, 1-35. [CrossRef]

5. Mikkonen, I.; Khan, I. Cloud Computing-SME Company Point of View. In Management Challenges in the 21st Century; Vysoká škola manažmentu: Bratislava, Slovakia, 2016; pp. 59-79.

6. Low, C.; Chen, Y. Understanding the determinants of cloud computing adoption. Ind. Manag. Data Syst. 2011, 111, 1006-1023. [CrossRef]

7. Rahayu, R.; Day, J. Determinant Factors of E-commerce Adoption by SMEs in Developing Country: Evidence from Indonesia. Procedia Soc. Behav. Sci. 2015, 195, 142-150. [CrossRef]

8. Radu, A.-V.; Niculescu-Ciocan, C.; Stoica, I. Marketing communication tools and technologies in the digital economy. In Proceedings of the International Multidisciplinary Scientific Conference on Social Sciences and Arts-SGEM, Albena, Bulgaria, 24 August-2 September 2019.

9. Tașcu, A.-V.; Radu, A.-V.; Stoica, I.; Dobrescu, A.-I. Online decision purchase process of medicines. Farmacia 2017, 65, 19-22.

10. Radu, A.-V.; Tașcu, A.-V.; Stoica, I.; Radu, A.-C.; Purcărea, V. Online instruments used in pharmaceutical marketing. Farmacia 2017, 65, 317-322.

11. Ceptureanu, E.G.; Ceptureanu, S.I.; Bologa, R.; Bologa, R. Impact of Competitive Capabilities on Sustainable Manufacturing Applications in Romanian SMEs from the Textile Industry. Sustainability 2018, 10, 942. [CrossRef] 
12. Popescu, D.I.; Ceptureanu, S.I.; Alexandru, A.; Ceptureanu, E.G. Relationships between Knowledge Absorptive Capacity, Innovation Performance and Information Technology. Case study: The Romanian Creative Industries SMEs. Stud. Inform. Control 2019, 28, 463-475. [CrossRef]

13. National Institute of Standards and Technology, NIST. The NIST Definition of Cloud Computing. 2011. Available online: http://csrc.nist.gov/publications/nistpubs/800-145/SP800-145.pdf (accessed on 11 February 2020).

14. Kurwitz, J.S.; Kaufman, M.; Halper, F.; Kirsch, D. Hybrid Cloud for Dummies, 2nd ed.; John Wiley \& Sons: Hoboken, NJ, USA, 2012.

15. Dumitrache, M. Cloud Computing-O nouă etapă în dezvoltarea internetului. Rev. Rom. Inform. Autom. 2014, 24, 40-48.

16. Layo, I. Cloud Computing Advantages for SMEs. 2013. Available online: http://cloudtimes.org/2013/09/18/ cloud-computing-advantages-for-smes/ (accessed on 20 January 2020).

17. Ajith Singh, N.; Hemalatha, M. Cloud Computing for Academic Environment. Int. J. Inf. Commun. Technol. Res. 2013, 2, 97-101.

18. Abdollahzadegan, A.; Hussin, A.R.C.; Gohary, M.M.; Amini, M. The Organizational Critical Success Factors for Adopting Cloud Computing in SMEs. J. Inf. Syst. Res. Innov. 2013, 4, 67-74.

19. Ližbetinová, L.; Štarchon, P.; Weberová, D.; Nedeliaková, E.; Jur`íková, M. The Approach of SMEs to Using the Customer Databases and CRM: Empirical Study in the Slovak Republic. Sustainability 2020, 12, 227. [CrossRef]

20. Zainuddina, N.; Nurazean, M.; Wardah, Z.A.; Nurul Huda, F.A.; Ganthan, N.S. Cloud Computing Adoption Conceptual Model of Malaysian Hospitals. Open Int. J. Inform. 2015, 3, 1-10.

21. Rao, T.; Venkat, N.K.N.; David, R.; Sathya, M. A New Computing Environment Using Hybrid Cloud. J. Inf. Sci. Comput. Technol. 2015, 3, 180-185.

22. Sosinsky, B. Cloud Computing Bible; Wiley Publishing: Indianapolis, IN, USA, 2011.

23. Padilla, R.; Milton, S.; Johnson, L. Components of service value in business-to-business Cloud Computing. J. Cloud Comput. 2015, 4, 1-20. [CrossRef]

24. Hamburg, I. Improving e-learning in SMEs through cloud computing and scenarios. In E-Learning-Instructional Design, Organizational Strategy and Management; Gradinarova, B., Ed.; InTech: Rijeka, Croatia, 2015; pp. 481-498.

25. Ayyagari, M.; Beck, T.; Demirguc-Kunt, A. Small and medium enterprises across the globe. Small Bus. Econ. 2007, 29, 415-434. [CrossRef]

26. Cătoiu, I. Cercetări de Marketing—Tratat; Uranus: Bucharest, Romania, 2009.

27. Bolton, R.N.; Drew, J.H. A multistage model of customers' assessments of service quality and value. J. Consum. Res. 1991, 17, 375-384. [CrossRef]

28. Benlian, A.; Koufaris, M.; Hess, T. The role of Saas service quality for continued Saas use: Empirical insights from Saas using firms. In Proceedings of the ICIS 2010 Proceedings, St. Louis, MO, USA, 12-15 December 2010; p. 26.

29. Davis, F. Remarked usefulness, remarked ease of use, and user acceptance of information technology. MIS Q. 1989, 13, 319-340. [CrossRef]

30. Adams, D.; Nelson, R.; Todd, P. Remarked usefulness, ease of use and use of information technology: A replication. MIS Q. 1992, 16, 227-247. [CrossRef]

31. Davis, F. User acceptance of computer technology: System characteristics, user perceptions and behavioral impacts. Int. J. Man-Mach. Stud. 1993, 38, 475-487. [CrossRef]

32. Chau, P.Y.K.; Tam, K.Y. Factors affecting the adoption of open systems: An exploratory study. MIS $Q$. 1997, 21, 1-24. [CrossRef]

33. Asghari, S.; Navimipour, N.J. Nature inspired meta-heuristic algorithms for solving the service composition problem in the cloud environments. Int. J. Commun. Syst. 2018, 31, e3708. [CrossRef]

34. Ooi, K.-B.; Lee, V.-H.; Tan, G.W.-H.; Hew, T.-S.; Hew, J.-J. Cloud computing in manufacturing: The next industrial revolution in Malaysia? Expert Syst. Appl. 2018, 93, 376-394. [CrossRef]

35. Arvanitis, S.; Kyriakou, N.; Loukis, E.N. Why do firms adopt cloud computing? A comparative analysis based on South and North Europe firm data. Telemat. Inform. 2017, 34, 1322-1332.

36. Marston, S.; Li, Z.; Bandyopadhyay, S.; Zhang, J.; Ghalsasi, A. Cloud computing-The business perspective. Decis. Support Syst. 2011, 51, 176-189. [CrossRef] 
37. Bayrak, T. A decision framework for SME Information Technology (IT) managers: Factors for evaluating whether to outsource internal applications to Application Service Providers. Technol. Soc. 2013, 35, 14-21. [CrossRef]

38. Kumar, D.; Samalia, H.V.; Verma, P. Exploring suitability of cloud computing for small and medium-sized enterprises in India. J. Small Bus. Enterp. Dev. 2017, 24, 814-832. [CrossRef]

39. Alshamaila, Y.; Papagiannidis, S.; Li, F. Cloud computing adoption by SMEs in the north east of England: A multi-perspective framework. J. Enterp. Inf. Manag. 2013, 26, 250-275. [CrossRef]

40. Ratten, V. Continuance use intention of cloud computing: Innovativeness and creativity perspectives. J. Bus. Res. 2016, 69, 1737-1740. [CrossRef]

41. Awa, H.O.; Ojiabo, O.U.; Orokor, L.E. Integrated technology-organization environment (T-O-E) taxonomies for technology adoption. J. Enterp. Inf. Manag. 2017, 30, 893-921. [CrossRef]

42. Thong, J.Y.L. An integrated model of information systems adoption in small businesses. J. Manag. Inf. Syst. 1999, 15, 187-214. [CrossRef]

(C) 2020 by the authors. Licensee MDPI, Basel, Switzerland. This article is an open access article distributed under the terms and conditions of the Creative Commons Attribution (CC BY) license (http://creativecommons.org/licenses/by/4.0/). 